\title{
Internationalizing Instructional Methodology for Postgraduates in Green Manufacturing
}

\author{
Dianlei Geng ${ }^{1, a}$ and Yan Gan ${ }^{2, b^{*}}$ \\ ${ }^{1}$ International School, Wuhan University of Science and Technology, \\ Wuhan Hubei, 430081, P. R. China \\ ${ }^{2}$ School of Foreign Languages, Wuhan University of Science and Technology, \\ Wuhan Hubei, 430081, P. R. China \\ aroger.geng@wust.edu.cn, b cathegy@sina.com,
}

Keywords: Internationalization; Instructional methodology; Green manufacturing

\begin{abstract}
In order to further internationalize the postgraduate education in China, this article proposes that some advanced educational strategies and teaching approaches to the major courses in machinery manufacturing be adopted for training interdisciplinary experts in green manufacturing with a global vision. The internationalized instructional methodology discussed hereby requires the university to inculcate in students the frontier knowledge and engineering experiences and to hone their expertise skills in green manufacturing. Therefore the instructional strategies and objectives are repositioned in virtue of the frontier scientific achievements and engineering experiences contributed by the faculty, and an internationalized teaching and learning mode is employed for delivering the core courses. For ensuring the instructional quality, a corresponding evaluation system for the tutorials is built online at international standard. Some measurements for improving the language capability of the faculty are also suggested at the end of the article.
\end{abstract}

\section{Introduction}

By means of underlining the discipline advantage of academic fields and adopting internationally advanced research pedagogical ideas and methods, internationalizing the postgraduate education in the mechanical manufacturing and automation discipline will help cultivate wide-caliber and innovative talents in machinery manufacturing. Some exemplary cooperative projects of international education at master's level include: Joint training projects on the global political economics in Oxford University and Princeton university (2001); the scientific research cooperation via reciprocally offered elective courses and student exchanges between Cambridge University and Massachusetts Institute of Technology [1]; ERAMSMUS (a European united education system plan) implemented in the 12 EU countries (1987) [2]; the scientific research and teaching cooperative projects hosted by Japan's Kochi University for advancing the fields of agronomy and soil science and ecology in the developing countries in the Asia-pacific region [3].

In China, a number of first-class higher learning institutions such as Fudan university, Nanjing university, Zhejiang university, Wuhan university, Huazhong University of Science and Technology have successfully carried out international cooperative education at the postgraduate level. Other examples of high-profile 985 universities that are successful in this regards include Kunming University of Science and Technology, Jiangsu university of Science and Technology, etc. One particularly exemplary cooperative project is jointly between Huazhong University of Science and Technology, Xi 'an Jiaotong University and the University of Michigan in the model of $3+1$ and $2+2$. In the program, the majority of the graduates continue to study for a master's degree in the University of Michigan. The major courses of the international education projects mainly include mechanical design and manufacturing, engineering thermodynamics, motor structure, power train, and traffic engineering, etc. 
A few international education projects in mechanical manufacturing at the postgraduate level have been carried out, such as the cooperative education project between Suzhou institute of Science and Technology and the University of South Wales (2010), which set up three undergraduate majors in mechanical manufacturing and automation [4]. In 2004 Jiangsu Institute of Technology set up the professional courses in automation and machinery manufacturing in partnership with German Hochschule Merseburg [5].

Obvious problems between education resources and talents disequilibrium flow to developed countries have become the biggest challenge for internationalizing education practice in mechanical manufacturing in China [6, 7]. Thus, establishing international exchanges, cooperation and coordination mechanism and intervening is an important way to promote international competitiveness of China's higher education. Through international strategy research on world first-class universities of higher education, Chao Deng, director of Chinese Education Center in Columbia University points out that the main methods of implementing higher education internationalization strategy include: two-way flow of teachers and students, professional courses teaching in line with international standards, and close cooperative partnership between colleges and universities $[8,9,10]$.

With its stronger scientific research achievements in the expertise area of green manufacturing, Wuhan University of Science and Technology (WUST) contributes plentiful education resources and engineering experiences to a joint program in mechanical engineering in collaboration with Deakin University, Australia. It is intended to impart students the frontier knowledge in the field and sharpen their expertise skills. Additionally, relying on the metallurgical equipment and key laboratories, the Research Center on Green Manufacturing and Energy Conservation and Emissions Reduction Technology and other scientific research arms at WUST have developed international education projects for the postgraduates in machinery manufacturing.

\section{Research Objectives and Instructional Objects}

The objectives of the research mainly target the core courses in machinery manufacturing pertained to mechanical engineering, namely, to carry out research on internationalization of the teaching methods and teaching organization pattern, and to explore internationalization coordination mechanism and architecture system of different levels of the graduates education. The core courses in machinery manufacturing mainly involve those in the subordinated field of mechanical manufacture and automation, such as advanced manufacturing technology, sustainable manufacturing theory and method, mechanical CAD/CAM, system modeling and simulation, etc. [11]

As noted in the national medium and long-term education reform and development plan outline (2010-2020), we need to strengthen international exchanges and cooperation, adopt international advanced education ideas and experiences, introduce high quality education resources, and improve the level of educational internationalization in China [12]. Through this study, by means of absorbing advanced teaching methods, organization mode and management experience from first-class courses in machinery manufacturing in developed countries, we aim to creatively put forward teaching methods for delivery of graduate professional courses both in line with international standards and with its specific advantage, realize the two-way beneficial interactions between the internationalization course teaching and teachers-students communication, foster professional talents with a global vision.

\section{Internationalized Instructional Methods in Detail}

Reposition Instructional Strategies and Objectives for the Postgraduate Education in Green Manufacturing. Instructional strategies and objectives for the postgraduate education in green manufacturing are reoriented as: emphasizing on the cultivation of the students' global perspective, innovation ability and the consciousness of environmental protection; based on student-oriented teaching idea, focusing on students' self-learning ability and the engineering application ability; 
taking the advantage of domestic students' sturdy basic education background and intensive knowledge in the graduate courses with the international wide-caliber education mode to realize the combination of strong corporations.

Highlight the Disciplinary Advantages of Green Manufacturing and the Teaching Staff Should be Updated for Implementing the Internationalized Progress. Based on international cutting-edge research in machinery manufacturing, we should endeavor to implement the following measures: strengthening the introduction of the metallurgical engineering machinery to make students better understand the structure and properties of iron steel rolling equipment characteristics; cultivating students' concept of green design and environmental protection consciousness of green manufacturing to keep scientific values of sustainable development in the mechanical design and manufacture; underlining the cultivation of students' engineering hands-on ability and innovation ability, actively organizing students to participate in the international and domestic innovation design competitions of energy conservation and emissions reduction.

Employ the Internationalized Teaching and Learning Mode for Major Courses. By means of adopting the internationally advanced experience of teaching organization, we should strive to improve the students' ability to apply the knowledge instantly and prepare more classroom practice and seminars to develop the students' subjective initiative.

Based on the projects and heuristics teaching mode, we should aim to improve the practical ability of students by means of team-work assignments. The faculty is advised to choose assignment topics in the relevant field of equipment, typical structure and component design, with, say, three students grouped in each team for completing the design task together. The design results of each group can then be demonstrated in a class seminar, where comments and shared experience by all students are invited. Students' performance as indicated in the design results will contribute to an important part of the overall assessment in the course. As advocated in the task-based teaching mode, students' interest, enthusiasm and initiative in learning is greatly motivated, the students' personality, innovative spirit and team cooperation ability are given a full play.

Other strategies for internationalizing the teaching process include adopting the tutorial collective Q/A model and releasing the exercises through the network in accordance with the curriculum arrangement. Elaboration on the exercises will be made one by one in the collective Q/A class with teacher-student interactions such as asking questions, completing some steps and calculation in a limited time to check students' answers.

Build Evaluation System Online for the Curriculum Tutorials at International Standard. Students' learning achievements in all courses will be evaluated through the cumulative assessments which include: a chain of regular homework assessments, experimental projects (experimental results), progressive assessments (quizzes), and the final exam (paper).

Curriculum evaluation is mainly conducted in the form of written tests and oral tests in English.. The group task performance results accounts for a certain share, say, 40\%, of the final grade. Semi-pen-book examination can be adopted in the form of a written test. In such test, a moderate percentage, for example, $20 \%$, of test questions are given to be answered in English, possibly with access to specified reference books.

The oral test in English is given as a supplement to the written test, which only the top one-third students are qualified to attend. In the test, exam questions concern the basic knowledge of the curriculum, which are intended to examine the students' expression skills. The oral test results will contribute contain portion of certain weight to the total score.

Improve English Language Teaching Capability of the Faculty. Combine language learning with professional knowledge to improve students' cross-border learning adaptability. Students will be able to use English to do daily communicate and read academic literature with the help of reference books via intensive language learning. The main teaching materials of machinery manufacturing professional course include specified original English materials and Chinese teaching materials; 
In respect of teachers and teaching organization, an English teacher supplements a Chinese teacher to keep normal English and academic English in same pace; send teachers to study abroad to improve the English teaching level via cooperation with foreign universities.

\section{Conclusions}

In contemporary China, internationalization of high education has become an irresistible trend under the waves of globalization. It plays a significant role in cultivating the innovative talents with profound expertise knowledge and global visions. Boosted by their strong scientific research achievements, many Chinese universities are committed to dedicating plentiful scientific resources and engineering experiences to the operation of their education programs, such as those in the area of green manufacturing where students are taught the frontier knowledge and accumulate international pedagogical experience. This practice is believed to better equip students with fundamental knowledge, expertise and relearning capacity in their chose field as well as a global outlook, science literary and innovative mind, which are needed in a successful career in the modern society.

\section{Acknowledgements}

The authors would like to acknowledge the funds supported by the following granted projects: the Research Project of Chinese Society for Academic Degree and Graduate Education (2015Y0507), the Educational Research Program of Hubei Province (2015224) and the Key Educational Project of Wuhan University of Science and Technology (Yjg201506).

\section{References}

[1] Smith A. Going international: In quest of a new "foreign policy" for European Higher Education. Going international: EU Higher Education, IIE Network, 2007

[2] Van Wende M., T Kalver Mark, etc. The relationship between national policies for internationalization and those for higher education in general [A]. National Policies $f$ or the Internationalization of Higher Education in Europe [C]. Stockholm: Hogskoleverket Studies, National Agency for higher Education. 2007.

[3] Hong Song. Review and respond to internationalization of higher education frontier problem. Academia, 2008.11; (6): 17-24.

[4] Jianfeng Yang. Mechanical professional personnel training mode based on Chinese-foreign cooperation in running schools research. Electricity education in China, $2014 ;(14): 32-33$.

[5] Hong-xiang Xu, Yan Sheng. Practice and exploration on cooperation education in Sino-German mechanical professional courses. Vocational education communication, 2014 ; (21) : 7-10.

[6] United Nations Educational, Scientific and Cultural Organization. Policies for the reform and development of higher education. 1995.

[7] Tang, M., Yu, z. the Internationalization of who education in China and Japan. New York: Center on Chinese education, head of the College of Columbia University.

[8] Manchao Zeng, Meixin Wang, Le Lin. The internationalization of higher education in the United States, Britain, Australia. Peking University education review, 2009.4; 7 (2) : 75-75, 102.

[9] Changgui Chen, Li-xia Weng. Internationalization of high education and innovative talents training. Higher education research, 2008.6; 29 (6): 77-82

[10]Li Zhuang, Hong Fang, Research and practice on talent training mode of international cooperation education [J]. Journal of Heilongjiang institute of education, 2010, 29 (10): 11-12. 
[11] Gang Zhao, Ping Tao, Xiang Zhang. Study on the Engineering Knowledge in the Curriculum Instruction of Mechanical Manufacturing. Advances in Economics, Business and Management Research, Part I: Education, Management, Information and Medicine Research, April 2015; 8: 1394-1398.

[12] Gang Zhao, Liangxi Xie, Gongfa Li. Making the higher education different from what happened in the last decade: A strategic vision of innovation and internationalization. Advances in Education Research. Mar. 2014; 52 (4): 318-324. 